\title{
New Directions in Higher Education in the Post COVID-19 Era-Global Perspective
}

\author{
Gurudutta P Japee \\ \{profgurudutta1@gmail.com\} \\ University School of Commerce, Gujarat University, Ahmedabad- India
}

\begin{abstract}
Since last two years higher education institutions [HEI] have been trying to answer following two questions. What features the universities of the future will have? What should be done by professors, administrative staff and university leadership to be prepared for the future? Various educational organizations are under the process of evolving and adapting newer trends of knowledge dissemination. HEIs are under opinion to adopt blended learning, flipped classroom, and many other technology-driven changes in teaching and learning brought by the COVID pandemic. Faculty and staff are getting acquainted with digital learning permanently, as they will be forced to reconstruct their academic programs for skill development and rapid employment. Universities will become GREEN and more aware of health and hygiene issues. Universities will be forced to do more with less revenue. These are the emerging issues and challenges faced by all higher education institutions. This paper is an attempt to redefine few higher education notions in detail.
\end{abstract}

Keywords: Discipline of Learning; Self-reflexivity; Dark emotions; Philosophy of Quality; TARAL

\section{Discipline of Learning}

Education is training of the senses to be receptive and sensitive of the mind, to control the senses of intelligence to be discriminative to give right direction of the body to be able to host the self, which is the part of the total consciousness. Triguna or three qualities tamas (Idle or inert, narrow), rajas (active dominating adventures) and sattva (enlightened, quiet)- are said to be constituents of human nature. Quality education facilitates the moment from tamasic to rajasic and to the sattvic stage, and can go beyond the three stages, i.e. the state of Triguna tita.

Shikshavalli, in the taittiriopanished, provides a new way to look at education; "the teacher is the prior form; the pupil is the later form. Knowledge is their junction; instruction is the connection" (Radhakrishnan 1998). Importantly it doesn't accept the conventional view of the transfer of knowledge from teacher to student as education. Instruction is the connection and knowledge is the junction. This view gets further expanded in the Upanishad invoking the God to bless both the Guru and disciple to learn together and seeking the grace of God so that one doesn't become jealous of the other. It emphasizes the importance of the continuity of learning, which was also reflected in Tagore's writing about the teacher; "A candle that does not continue to burn itself, cannot light another".

In one of the approaches Indian scriptures recommended 4 stages learning process for quality; listening, studying, teaching and applying. The four-stage learning asserts first, that 
any one source is not enough. It also offers a taxonomy of learning; as one move from listening to application, it is non-hierarchical, there is complementarity and it is non-exclusive. The multi-channel learning paradigm was also professed in the hastanasatak of the great epic Mahabharata; "a quarter of the learning accrues each from the teacher, self-study and talent, interaction with peers, and rest with time through experience." Following image depicts how taxonomy of educatedness works (Mukhopadhyay, M).

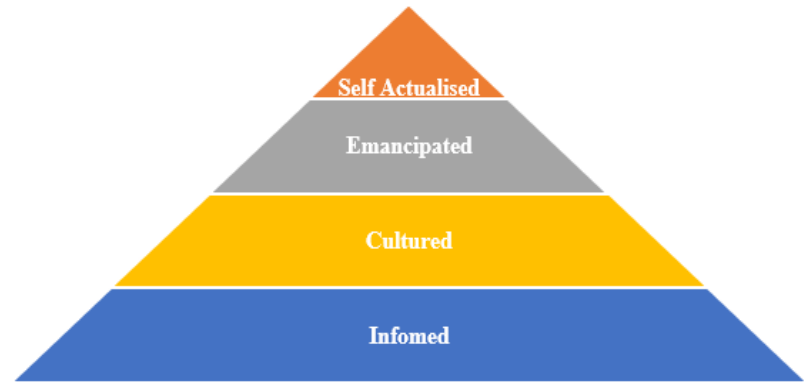

Fig 1. Taxonomy of educatedness

The existing education systems which are or will be no longer relevant and beneficial in the forthcoming years, therefore will have to establish and develop newer systems or department of learning (Discipline of learning) wherein, first to unlearn the prevailing knowledge which is no more effective in present situations, which are simply mimeses and pseudo knowledge and learn the innovative notions to attain sustainable education organization

\section{Role of Teachers}

Becoming a teacher is a hard task and to be a teacher is still harder. Role of teacher has become more challenging now a days. In many higher education institutions teachers are paid on the basis of their performance while in many institutions they are awarded and rewarded with their outstanding contribution in research, teaching and learning, innovation and social outreach activities. Effective and efficient teacher in the digital age is even more complicated as it is not only demanding domain specific knowledge but also the knowledge of information technology and electronic evidence management.

What do I need to know? What have my students learn? What is the best way to teach students? How do I create and maintain an effective learning environment? How can I organize and facilitate collaborative learning? What new learning networks I can join? What will I teach? What are the current trends in Research? Where do I publish my research papers? What are the resources available? and how can I maintain the relationship with past students and play role of advisor for them? Such questions are very common now a days in teaching fraternity.

This paper is developed to help teachers and higher education institutions. It is intended to help teachers and management to evaluate their performance on yearly basis. TARAL is the manual designed for higher education teachers to evaluate their performance in particular academic year. 


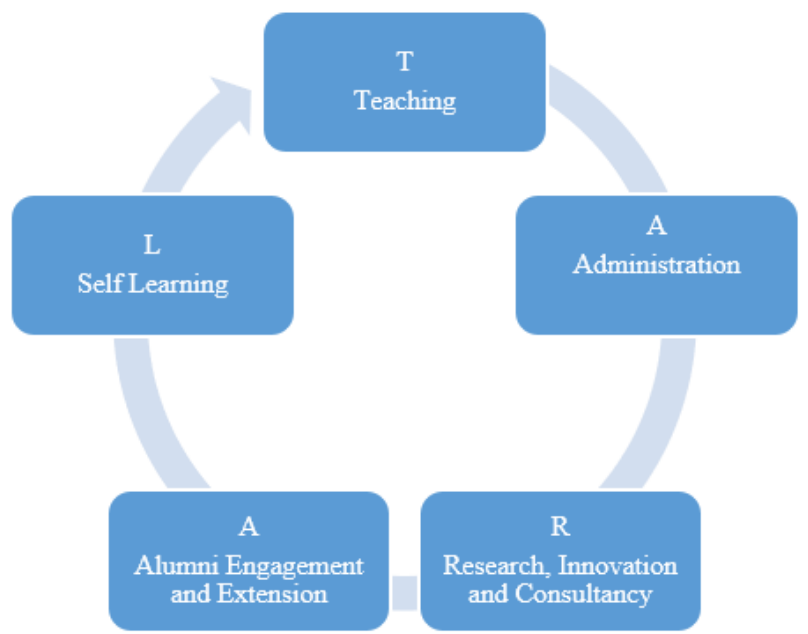

Fig 2. TARAL

In earlier 1990's teachers had the monopoly of knowledge where they used to engage class and deliver the knowledge. Today knowledge is not the monopoly of teachers. Students get knowledge from millions of online resources available on websites. Teachers are no longer a sage on stage, teachers should enhance the quality of teaching and learning through digitization. The role of teachers is now limited to facilitation, to facilitate how students should get the right knowledge, how they should synthesis the knowledge from various resources. Students are not consumer of knowledge they are now producer of knowledge too. Teachers in coming era should focus on TPACK model for teaching and learning purpose. Following figure depicts TPACK Model.

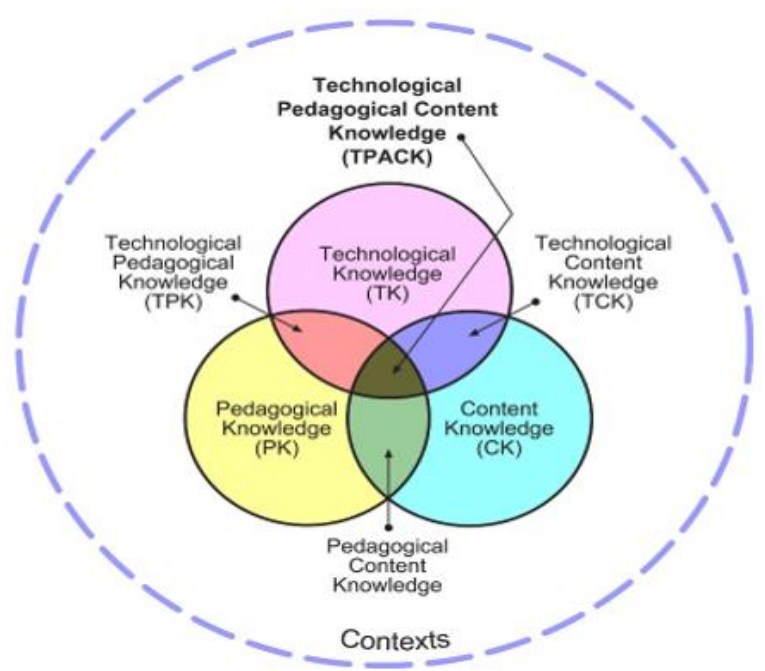

Fig 3. TPACK Model

(Source: image @2012 by tpack.org) 


\section{Redefining Quality}

Functional Quality is what quality does. As important as quality is, there's little agreement on its definition. Perhaps the foremost useful business definition of quality is "fit for the purpose". This definition evolved in quality management circles. It is useful because it is applicable to any process, service, or product. However, Quality is usually measured in terms of performance to requirements. This definition is right for quality assurance teams that require validating processes, systems, services, and merchandising quality. Quality is compliance to best known standards, processes, and specifications. Quality may be a satisfying experience.

\subsection{The Origins of Quality}

In 45 B.C., the Roman statesman and philosopher Cicero created the Latin term qualities in his introduction to Greek philosophy. Today, it's a word used frequently in many languages, but to the Greeks, it had been a technical philosophical word. The term goes back to a linguistic innovation by Plato in his dialogue Theaetetus where Socrates asks the question "What is knowledge?"

Socrates started his quest to seek out what knowledge is by taking over the lurking trap of the relativists, Protagoras and Heraclitus. Both meant that the world was in constant flux which the sole thing we could know was the experiences we get through our perceptions, or as Protagoras formulated it:

"Man is the measure of all things."

That was not the view of Plato. The short section where Plato introduces "quality" isn't that easy to interpret, he established the term quality as something that describes persistent characteristics of our reality that exists in and by itself, that aren't reducible to something else. Whiteness, for instance, exists as a character in itself.

This is considerably the view that Plato's great pupil Aristotle also held. In his book on logic, Organon, he develops the concept of ten different categories we use to explain the world once we make propositions. The foremost important of the categories is that the substance, which in some way is that the more famous Plato "idea" embedded actually. The substance of a chair is what makes it a chair, regardless of what other categories you'll express about it.

Objects even have other characteristics, for instance, an object is often during a place, or it is often moving. Another aspect of an object also can be measured, for instance, its height, which he calls the quantitative category. However, an object also has qualities.

"By 'quality' I mean that in virtue of which individuals are said to be such and such," writes Plato.

"The body is named white because it contains whiteness."

Thrust for quality is a civilizational phenomenon, wherein humanity aspires for qualitative change. Till 1990 quality was more associated with products, but now it has become a canopy concept. In last couple of decades quality of human services have started expanding use through the term quality. Telecom business, insurance business, banking business, aviation industry and education too, though it has ensured its commodifying use or commodification. The basic question is, which needs to be answered is what is philosophy of quality?

Asking for the quality in education is an outcome of modernity. Modernity is an archaeological construction of institution. Even an individual is also identified in the guise of archaeological construction of the institution which leads to identity crisis at both levels. 
Educational institutions have started using the term quality only in modern era. Institutionalization of education made quality as it is a measuring tool.

Assertion (implies understanding) and Contemplating (without contemplating it is mere data collection or quantification) about quality helps us for the functional betterment. It enriches the potential for quality enhancement, for which negotiation of presumed discourse is necessary, it entertains and dislodges the non-qualitative discourse. Quality is a forward approach. It incurs the possibilities for negotiation, without having possibilities to negotiate, discourse of quality cannot be possible. Non-negotiable discourses impede the primary condition of quality. Furthermore, discourse should not be based on the ethics of hierarchical power or committed ideological framework.

To know the philosophy of quality, we have to contemplate over it. Reflecting about quality is the basic theme of the philosophical inquiry. There are three questions to ensure quality in any sector.

a. Can quality have gradation?

b. Can quality be evolved?

c. Can quality be classified or how to classify the quality? quality.

There are two important aspects in the quality is the defining quality and analyzing the

When any institution is defining quality for their product or services, they must make a rational examination of their own concept of quality. Rational inquiry is a navigating force of entire discourse about quality. Whether they are rational or not basic assumptions of the concept should be examined and to be substantiated. Whether it is valid or not, even the criteria for validation should also be examined. It is purely rational inquiry, which is context free, if it includes the context means it has plurality which is against the philosophy of quality as it is singular in approach. However, it is required to understand the nature of contextuality.

Contextual is the phenomena wherein domain or subject is one and perceptions and interpretations are different. There can be two possibilities when we discuss contextuality. Rational grounding, reasoning and substantiality are the basic assumption which are lying in the definition. Whether they are rational or not basic assumption is to be substantiated or examined, logical foundation or reasoning must be examined. Whether it is valid or invalid. Criteria of validation must be there. However, the nature of contextuality should also be understood by those who implement the quality. There are three possibilities

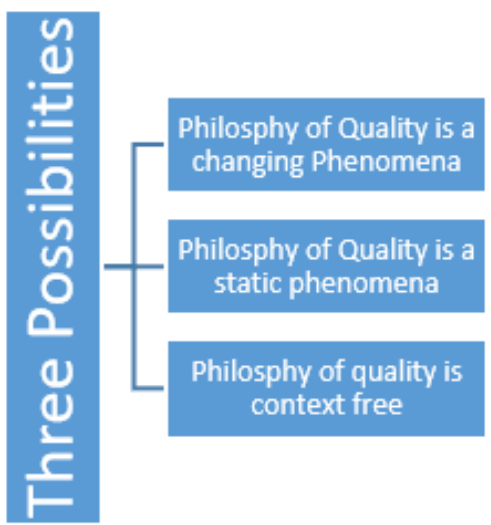

Fig 4. Three Possibilities 
When it is claimed that philosophy of quality is a changing phenomenon means it has variability, contextuality, it has an element of change. Such dynamic domain has many perceptions. To consider the quality as static phenomena are context dependent wherein one context is set as a universal concept. While the third concept wherein philosophy of quality is context free which is not based on causality. Here rational inquiry is a navigating force of the entire discourse about the quality. To make the discourse on philosophy of quality four pillars are required to be discussed first.

One it is changing phenomena and other it is static phenomena. The earlier one is dynamic and changeable which is variable context. The latter has a specific context dependence or it has a set of contexts which is the universal concept of contextuality. Philosophy of quality is related to a context free approach; and not dependent on any causality.

\subsection{Quality as Emergent Property:}

Quality may be viewed as an emergent property. Emergence is, in the words of Aristotle in Metaphysics, "the whole is quite the sum of its parts." Quality, then, would be the new level of experience, the mixture of the three Kantian aspects into one whole. Looking from this attitude, the thought of anything a customer buys being quality would be ludicrous. If I buy something I can afford to satisfy my needs, it doesn't in itself mean that I view the thing I bought as a top-quality product, i.e. a mixture of robustness, usefulness, and wonder.

\subsection{Four pillars of Quality}

What is the dialectic of philosophy of quality? Is the vital question to be answered by all institutions? To understand it, following pillars of quality must be implemented.
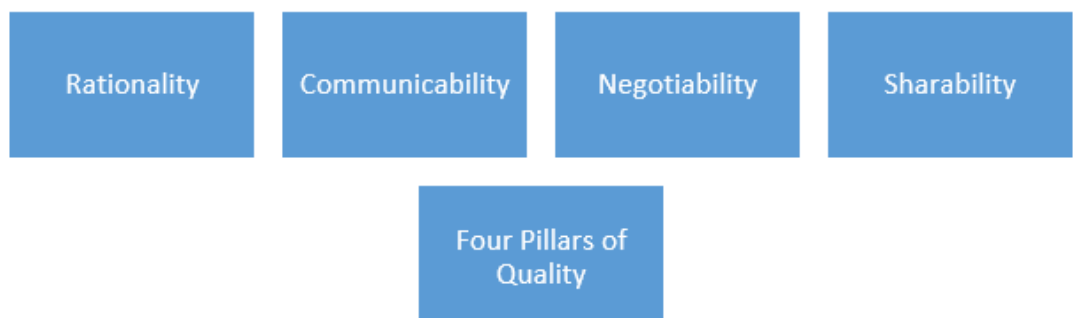

Fig 5. Four pillars of Quality

In the absence of above four pillars, quality cannot be meaningfully framed, qualitative discourse cannot be exhibited or would be possible.

\subsection{Rationality}

Basic element of rationality is reflexivity. (To think is to reflect)- Thinking without reflection is not possible. Reflexivity by oneself and by other are two types of reflexivity. One can examine his own premises, conclusion and its relation. Thinking is not possible without premises, through argumentative substantiation, to arrive at conclusion. First and foremost, process of thinking requires premises after which it substantiate either through evidence or through reasoning.

Evidence is needed to substantiate the premises, similarly there is another technique to substantiate premises is to give reason. Without premises thinking becomes imagination. Conclusion is decision making but when it is derived without premises the entire process 
becomes illogical therefore, thinking should be logical only when it has is based on premises there is a difference between thought and thinking otherwise it is mere unconnected thought process (mental activity). Rationality is a part of such thinking process. To be logical is to be rational or to be rational is to be logical.

\subsection{Communicability}

Communicability is a meaning sharing devise. Understanding of sign- symbol or language is required in communication and both parties involved in communication must understand when shareability of meaning is missing communicability hinders. Following diagram shows how communicability functions.

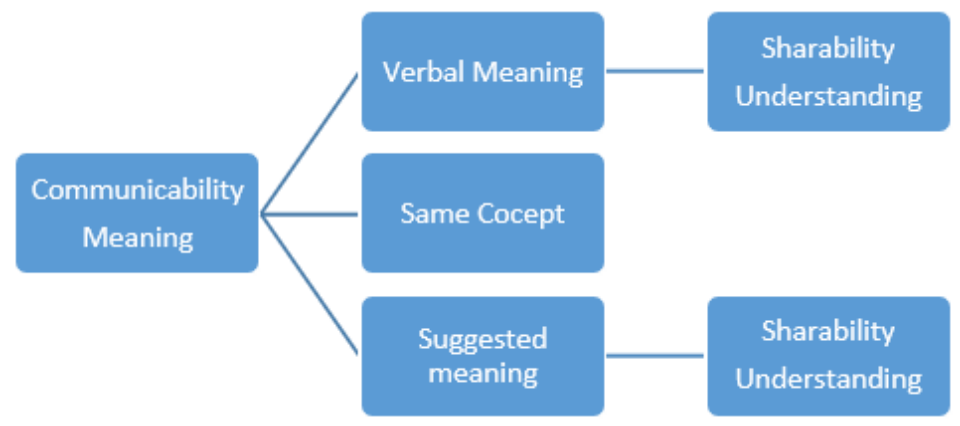

Fig 6. Meaning of Communicability

Apart from verbal meaning, suggestive meaning is equally important. Further, primary and secondary meaning both are important. Knowledge/ competency of language is must for proper communication which leads to quality. Competency must be cultivated. Communication is something which is apt. It needs to be explored and should be selfcultivated. It can be generated, or it can be more pertinent.

\subsection{Negotiability}

There is a difference between communicability and negotiability. In negotiability element of argument is included. Arguments are of two types. Argument for truth and argument for falsity. Negotiation is a search for either truth or falsity. Negotiation is an inquiry or assertion for acceptability.

\subsection{Shareability}

Negotiability and communicability is not possible without shareability. The quality of being sharable or the likelihood of being shared. Shareability refers to the extent to which information is shareable. Information has high shareability if it is easy to share between different individuals without loss of fidelity. Shareability theory (Freyd 1983, 1990, 1993) proposes that internal (e.g. perceptual, emotional, imagistic) information often is qualitatively different from external (e.g. spoken, written) information, and that such internal information is often not particularly shareable.

The theory further proposes that the communication process has predictable and systematic effects on the nature of the information representation such that sharing information over time causes knowledge to be re-organized into more consciously available, categorical, and discrete forms of representation. 


\subsection{Philosophy of Quality in Higher Education}

System transcendence is the primary requirement in quality or for the quality to function. Domain must be reviewed from historical context and to check whether knowledge content has been improved or not. Sometimes knowledge content may fall down. It is cultivating phenomena because the entire education system is only teaching and discussing even the history is discussed in the form of chronology. How to extract knowledge from dogmatic narration and what are the types of practice performed for it are the basic questions to be asked to the academy of higher education institutions for quality. Otherwise, such academy would turn into a dogmatic slumber.

To establish quality in higher education, reviewing the status of knowledge is important. Capital of current academia is ignorance; hence Archaeology of knowledge construction is just in case of reviewing. Academic institutions must have a system of transcendence, it must have potential to grow. It is possible by practicing review + evaluation approach and not revision + evaluation approach. System transcendence is the requirement for quality transformation. To transcend means qualitatively going beyond. There is a difference between change and transformation.

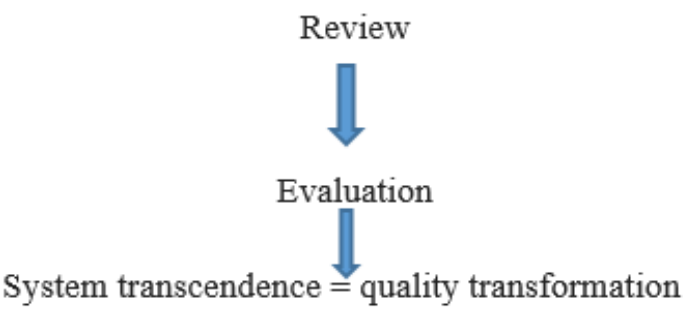

\subsection{Subject Ness}

Without subjectivity quality cannot be experienced. Quality cannot be determined without the reference of subjectivity. To function with quality subjectivity is inevitable. Anatomy of quality has both objective and subjective experience. Anatomy of quality cannot rest on the exclusion of object and the experiencer. Category of space and time must be kept in mind to perceive the quality. Space and time experience is apriori construction of one's own consciousness. It is universal and apriori. Any object cannot be perceived without a category of space and time. For the recognition of an object or phenomena one requires subjectivity or consciousness. Subjectivity can't be nullified.

\section{Self-Reflexive Skills}

\subsection{Role of Self Reflexivity in Higher education}

Instead of monolithic structure of governance, we require nonsingular structure of governance that can put stress on two academic values i.e., freedom and quality. Which in turn, would serve the global academic demand, at the same time; it will nurture identity, which would serve for global unification. The backbone of harmony can be integration and prejudice free living. Dogma learning will indulge into dogmatic learning. For the said purpose it is required the questioning spirit. Questioning spirit is the pursuit of inquiry, will take place and the pursuit would enter into the domain of self-learning process. This reflects one basic skill of self-reflexivity exemplified by the responses. This self-reflexivity is the hardcore of any 
academic enterprise. Such skills can be nurtured by putting more emphasis on creativity and critical thinking.

\section{Quality of life}

Being, belonging and becoming are three life domains concerned with quality of life. Currently the Higher education systems were engaged in imparting knowledge about quality of life focusing on becoming and belonging. Becoming domain promote, maintain and improve knowledge and skills helping in personal being and leisure being. While belonging domain classified in two categories i.e. physical belonging and social belonging and community belonging, Which addresses the individuals connections with environments of home, society and community.

The current pandemic situation and other disastrous changes in current life style now demands that the quality of life of individuals should be more towards being. Being is further classified into three sub domains which are physical being, psychological being and spiritual being. The different stress and their impact on quality of life in existing state, weighs the importance of physical health, psychological health and spiritual health incorporated in the domain of being.

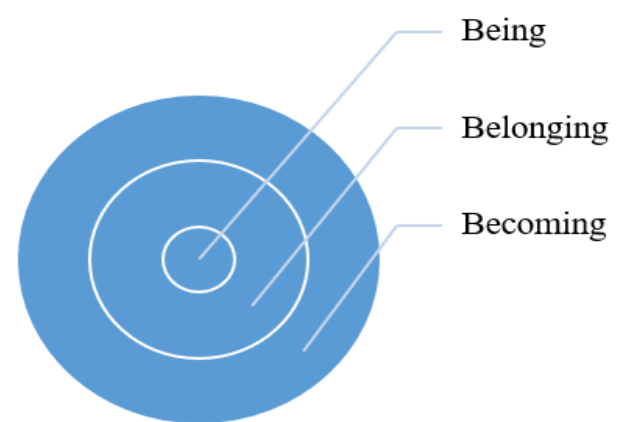

Fig 7. Quality of Life

\section{References}

[1] Acharyat Padamdate padam shishya swami dhaya, padamekam swabrhmachirvi, padam kala kramena hi

[2] Acarya Purva- Rupam, Antevasi Uttrarupam, Vidhya sandhi Pravachana samdhanam, iti adhuividyam.

[3] Freyd, J.J. (1983) Shareability: the social psychology of epistemology. Cognitive Science, 7, 191210.

[4] Freyd, J.J. (1990) Natural selection or shareability? [commentary] Behavioral and Brain Sciences, $13,732-734$.

[5] Freyd, J.J. (1993) Five hunches about perceptual processes and dynamic representations. In Meyer, D. \& Kornblum, S. (Eds) Attention \& Performance XIV: Synergies in Experimental Psychology, Artificial Intelligence, and Cognitive Neuroscience - A Silver Jubilee (pp. 99-119). Cambridge, MA: MIT Press.

[6] Japee, G.(2018), Improving Quality in higher Education by self-reflexivity skills, Root Throne and Crown of Higher Education, Authors press, New Delhi, India

[7] Japee, G.(2019), In Pursuit of World Class University, Aadi Publishers, Jaipur India (pp. 10-16) 
[8] Kanji, G \& Asher, M(2016), 100 Methods for total Quality management, Sage Publications India Pvt limited.

[9] Mukopadhyay,M.(2020) Quality in Education,Total Quality Management in Education, Sage Publications India Pvt limited, (pp.10-13).

[10] Raphel, D, Rukholam,E., Brown,I.,Hill bailey,P., and Donato,E(1996) the quality of life profile Adolescent version; Background, description, and initial validation, Journal of Adolescent health, 19(5), 366-375

[11] Saha Nababatu, Saha nau bhunaktu sahaviryam karabvahe tejasvina vadi tamstu ma vidvishavahi.

[12] https://educationaltechnology.net/technological-pedagogical-content-knowledge-tpack-framework/ 